\title{
Cardiological Society of India
}

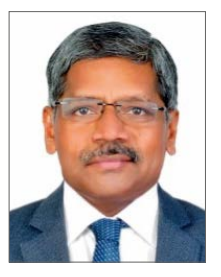

Padhinhare P. Mohanan*, MD, DM; President Cardiological Society of India

Westfort Hi-Tech Hospital, Kerala, India

Located in South Asia, India sits on a peninsula that extends between the Bay of Bengal and the Arabian Sea. India is the world's second most populous nation and is the birthplace of Hinduism and Buddhism. As the world's largest democracy, India is a federal republic with 29 relatively autonomous states and seven union territories. English is the most important language for national, political and commercial communication, but Hindi is the most widely spoken. The culture of India refers collectively to the thousands of distinct and unique cultures of all the religions and communities present in India. India's languages, religions, dance, music, architecture, food, and customs differ from place to place within the country. The Indian culture, often labelled as an amalgamation of several cultures, spans across the Indian subcontinent and has been influenced by a history that is several millennia old. Many elements of India's diverse cultures, such as Indian religions, Indian philosophy and Indian cuisine, have a profound impact across the world.

"If I were asked under what sky the human mind has most fully developed some of its choicest gifts, has most deeply pondered on the greatest problems of life, and has found solutions, I should point to India" said Max Mueller about India.
The Indian healthcare delivery system is categorised into two major components: public and private. The Government, i.e., the public healthcare system, comprises limited secondary and tertiary care institutions in key cities and focuses on providing basic healthcare facilities in the form of primary healthcare centres (PHCs) in rural areas. The private sector provides the majority of secondary, tertiary, and quaternary care institutions with the major concentration in metropolitan areas and tier I and tier II cities. India's competitive advantage lies in its large pool of well-trained medical professionals. India is also cost-competitive compared to its peers in Asia and Western countries.

Cardiovascular disease (CVD) is now the leading cause of mortality in India. Nearly a quarter of all mortality is attributable to CVD. Coronary artery disease and stroke are responsible for $>80 \%$ of CVD deaths. The age-standardised CVD death rate is $272 / 100,000$ in the population in India, much higher than the rate of 235/100,000 in the global population ${ }^{1}$. Premature mortality (years of life lost due to CVD) in India has jumped by $59 \%$ in the last 20-year period. Certain dimensions of CVD in India are of immense concern - early onset, rapid progression and a high case fatality rate. It is estimated that 62 million people in India have

*Corresponding author: Westfort Hi-Tech Hospital, Guruayoor Road, Punkunnam, Thrissur, Kerala 680002, India. 
some form of CVD compared with 36 million just a decade ago! The relentless growth of CVD in India should be curbed through preventive measures and by an optimal utilisation of resources to render care to millions of individuals with CVD.

The Cardiological Society of India (CSI: https://csi.org.in), the largest association of cardiologists in India, works towards the prevention of CVD and the reduction of cardiovascular mortality by raising awareness among its members, other healthcare professionals and the public. The story of the creation of our society makes for some interesting reading ${ }^{2}$. Bharat Ratna Dr Bidhan Chandra Roy (B.C. Roy) was instrumental in the official formation of the CSI which was founded even before the American College of Cardiology. A group of eminent physicians including Dr B.C. Roy and others were travelling on a train from Kolkata to Asansol, a suburban town, to attend a conference in 1946. On board the train, the idea of forming the Cardiological Society was mooted and discussed. Two years later, in 1948, the elite physicians of India met in Kolkata (then Calcutta) and the CSI came into being on 4 April 1948 with Dr B.C. Roy as founder President.

The first annual conference of the CSI was held in 1950 in Kolkata in association with the All India Medical Conference, and later in 1954, it was decided to hold the conference along with the Association of Physicians of India. From 1976 onwards, separate CSI conferences were held. Interestingly, the 5th World Congress of Cardiology was hosted by the CSI in 1966 at Delhi. The CSI became a founding member of the Asian Pacific Society of Cardiology (APSC) and a member of the World Heart Federation, the South Asian Association for Regional Cooperation (SAARC) Cardiac Society and works jointly with the European Society of Cardiology (ESC) and the American College of Cardiology (ACC). At the CSI annual meetings, which usually occur the first week of December, there are always joint sessions with many international societies. Annual meetings attract the entire cardiology community from India and nearby countries, and the best of the national and international faculties are invited to discuss contemporary topics. There are generally five orations and five award sessions each year and lifetime achievement awards are bestowed during this time as well. The fellows-in-training have ample opportunity to show their research and to learn. COVID19 has of course changed the schedules of many of our meetings. Our virtual educational offerings continue to adapt and evolve to meet the needs of clinicians who are fighting COVID-19 and heart disease. We started an educational programme for the fellows-intraining, wrote a consensus statement quickly and disseminated the knowledge amongst cardiologists and physicians in a timely manner. The pandemic brought us closer together as we were fighting a new enemy. This must continue, as our common enemy is heart disease and our common goal is a healthy life for all.

The COVID-19 pandemic has had an impact on healthcare systems all over the world, including India. It has affected the management of acute cardiovascular disease conditions, especially ST-elevation myocardial infarction (STEMI) - which in itself is challenging - despite the advances in reperfusion therapy. The reports on STEMI cases at the onset of the pandemic showed thrombus as the main cause, with few underlying flow-limiting lesions. Hence, during the early days of the pandemic, there were uncertainties regarding the best way to manage STEMI. Most of the guidelines from developed countries continue to recommend primary angioplasty as the initial treatment strategy even during the era of the COVID-19 pandemic. The CSI's position statement on acute myocardial infarction (MI) care during COVID-19 recommends that, in patients with a confirmed or suspected COVID19 infection presenting with STEMI within 12 hours of onset of symptoms, primary PCI should be preferred if performed with the necessary precautions and preparedness. If this is not possible, thrombolytic therapy is an alternative. If the clinical probability of a COVID-19 infection is low, follow the pre-COVID-19 strategy. The statement also recommends that thrombolysis should be preferred in small towns and villages, where cath lab facilities are not available.

The Society, including its overseas members, currently has a membership of about 4,600. The CSI has 26 state chapters which organise chapter meetings once or twice a year. The CSI has 15 sub-councils, comprising the National Interventional Council (NIC) and councils for Registry Data, Rheumatic Heart Disease (RHD), Cardiac Rhythm, ST Elevation MI (STEMI), Hypertension, Echocardiography, Imaging, Preventive Cardiology, Heart Failure, Lipid, Guidelines, Congenital Heart Disease (CHD), Master Class and Digital Technology.

The interventional wing of the CSI was established in 1985 , eight years after the first angioplasty procedure on a coronary artery was performed by the German-born physician, Andreas Gruentzig, in 1977. Although news of the feasibility of treating coronary artery disease interventionally spread across the globe rapidly after the first procedure, it took some time to construct a dedicated interventional subspeciality of cardiology in India. The revolution in the treatment of coronary artery disease was carefully passed down to successive generations to improve, year after year, through the Percutaneous Transluminal Coronary Angioplasty (PTCA) Registry Meet in India, which was renamed in 1999 the Midterm National Interventional Cardiology Conference. The current name - the National Interventional Council (NIC) - was adopted by the leading interventional cardiologists of India. Traditionally, the NIC organises a midterm meeting in the month of April and an interventional workshop, along with the annual CSI meeting, in December. It is currently estimated that an average of 1,500 interventional cardiologists are working in 4,185 cardiac catheterisation laboratories (CCL) in India. NIC also collects yearly data on all the vascular interventions performed in our country.

The Official Journal of the CSI, the India Heart Journal, had its modest beginning in 1949 in Calcutta with Dr J.C. Banerjea as its first Honorary Editor. It publishes sound scientific articles (both research and practice papers), focusing on topics that are of great importance to its readership. Every year the World Heart Day is observed at CSI headquarters (HQ) and all other branches of CSI 
on 29 September. Many years after its formation, the CSI is also focusing on research.

The CSI COVID AMI study ${ }^{3}$, a retrospective study that compared the pattern of admissions and management of acute MI in India during the COVID and non-COVID eras, showed that around $33 \%$ of patients with STEMI receive primary PCI, $37 \%$ thrombolysis and only $20 \%$ of those who received thrombolysis underwent pharmaco-invasive treatment. There was no significant difference in the frequency of primary PTCA between the two time periods, but thrombolysis increased and pharmaco-invasive strategy was less often employed during the COVID era. The first prospective study from the CSI, the Prospective REgistry of STEMI management in COvid era - INDIA (PRESCO-INDIA) is the largest study on the presentation and management of STEMI in India during COVID. Recruitment has begun and the study will provide insights into STEMI management in the country and its outcomes.

Women make up the majority of medical graduates; however, they comprise $<15 \%$ of practicing cardiologists and $<5 \%$ of interventional cardiologists. Gender inequality within cardiology and interventional cardiology is similar to that seen within general surgery and orthopaedics. Although cardiology is already a high-pressure work environment, women face extra challenges. The Indian cardiology community fondly remembers the untiring efforts of female cardiologist Padma Vibhushan Professor Padmawati, a past president of the CSI. There are also scores of erudite and hardworking cardiologists in the country who collectively built the foundations of our organisation and nurtured it to the present level.

The CSI exists because of its members. While we may work in different environments, live in different places, and speak different languages, our commitment to our patients is the essence of what we do. We help and we heal. This past year made it abundantly clear that we are all part of one global community.

Although this has been a year marred by so much loss, struggle and uncertainty, it has also been a year of hope, of strength, of resilience and adaptability and a year of courage. Thank you again to each and every one of you for all that you do for your patients, the profession and the society. I am reminded of the great words of Rabindranath Tagore, "where the mind is without fear, the head is held high". I wish for you a mental cosmos where you are confident individuals, not scared to face the most challenging tasks.

\section{Conflict of interest statement}

The author has no conflicts of interest to declare.

\section{References}

1. Prabhakaran D, Jeemon P, Roy A. Cardiovascular Diseases in India: Current Epidemiology and Future Directions. Circulation. 2016;19;133:1605-20

2. Das MK, Kumar S, Deb PK, Mishra S. History of cardiology in India. Indian Heart J. 2015;67:163-9.

3. Zachariah G, Ramakrishnan S, Das MK, Jabir A, Jayagopal PB, Venugopal K, Mani K, Khan AK, Malviya A, Gupta A, Goyal A, Singh BP, Mohan B, Bharti BB, Majumder B, Wilson B, Karunadas CP, Meena CB, Manjunath CN, Cibu M, Roy D, Choudhary D, Das DR, Sarma D, Girish MP, Wander GS, Wardhan H, Ezhilan J, Tummala K, Katyal VK, Goswami K, Subramanyam K, Goyal KK, Kumar K, Pathak LA, Bansal M, Mandal M, Gupta MD, Khanna NN, Hanumanthappa NB, Bardoloi N, Modi N, Naik N, Hasija PK, Kerkar P, Bhattacharyya PJ, Gadkari P, Chakraborthy RN, Patil RR, Gupta R, Yadav R, Murty RS, Nath RK, Sivakumar R, Sethi R, Baruah R, Tyagi S, Guha S, Krishnappa S, Kumar S, Routray SN, Tewari S, Ray S, Reddy SS, Chandra S, Gupta SB, Chatterjee SS, Siddiqui KKH, Sivabalan M, Yerram S, Kumar S, Nagarajan S, Devasia T, Jadhav U, Narain VS, Garg VK, Gupta VK, Prabhakaran D, Deb PK, Mohanan PP; CSI-AMI Study group. Changing pattern of admissions for acute myocardial infarction in India during the COVID-19 pandemic. Indian Heart J. 2021;73:413-23. 